\title{
Políticas Públicas de Comunicação Social e Liberdade de Expressão: os Casos da Argentina, Bolívia, Equador e Venezuela
}

\author{
Publi Policies of Social Communication and Freedom of Speech: \\ the CASES of ARGentina, Bolivia, ECUADOR and Venezuela
}

André Augusto Salvador Bezerra(")

Resumo: A implementação de políticas públicas de comunicação social em países da América Latina neste início de século tem sido objeto de intensos debates acerca de suas implicações para a liberdade de expressão. Em tal contexto, o presente trabalho analisa as medidas executadas sobre empresas midiáticas pelos governos da Argentina, Bolívia, Equador e Venezuela. Procura sustentar que as atuações governamentais destes países configuram casos de cumprimento do dever de promover efetividade ao direito à palavra contra os oligopólios da mídia empresarial privada.

Palavras-chave: Liberdade de expressão; Estado; democracia; mídia; América Latina.

\begin{abstract}
In Latin America, the implementation of public policies of social communication has been the subject of intense debate over its implications in regards to freedom of speech in the new century. In this context, the present work exposes a study of government policies over media companies in Argentina, Bolivia, Ecuador and Venezuela. The work sustains that the governments of those countries provide effectiveness to free speech against the corporate media oligopolies.
\end{abstract}

Keywords: Freedom of speech; State; democracy; media; Latin America. 


\section{INTRODUÇÃO}

A implementação de políticas de comunicação social por parte de determinados governos latino-americanos, no presente início de século, tem dado ensejo a amplas discussões acerca de suas implicações para a independência das empresas midiáticas e para a sobrevivência dos sistemas democráticos da região.

Neste sentido, são representativas as ponderações realizadas pela Sociedade Interamericana de Imprensa (SIP), entidade sem fins lucrativos, que se coloca na missão de defesa da liberdade de expressão em todo o continente americano. Por intermédio de comunicado divulgado a partir de Lima (18.10.2011), afirmou a associação que as ameaças contra a mídia independente especificamente na Venezuela, Equador, Bolívia e Argentina têm sido cada vez mais intensas, ora abarcando não apenas violência privada física contra jornalistas, mas também atos governamentais diretos, seja por intermédio de montagem de estrutura paralela de meios de comunicação estatais que buscam o desprestígio da mídia não oficial, seja por ofensas proferidas pelos próprios governantes, seja, por fim, pela promulgação de leis restritivas da atuação midiática. Tais críticas têm sido ressoadas pelas maiores empresas de comunicação da região, que, em geral, não medem esforços para, vez ou outra, opinarem em editoriais ou publicarem reportagens divulgando supostos casos de ameaças à imprensa livre por atos destes governos.

O quadro acima descrito merece, em princípio, justificadas preocupações. A divulgação de informações independentes ao discurso oficial pelos meios de comunicação insere-se na liberdade de expressão, o direito humano fundamental da palavra (LIMA, 2010 , p. 21). Cuida-se de valor essencial ao regular funcionamento da democracia, forma de governo que demanda o dissenso de ideias (BOBBIO, 2000, p. 73), normalmente fomentadas pelas informações transmitidas pela mídia.

O problema é que quando se fala de meios de comunicação no cenário deste século XXI, não se fala de uma imprensa plural, amadora e artesanal, tal como prevalente no período da instituição do Estado de Direito na Europa ${ }^{(1)}$ ou nos primeiros anos de independência política da América Latina diante das metrópoles ibéricas ${ }^{(2)}$. Fala-se, em verdade, de empreendimentos dotados de elevado capital e proeminente nível de racionalização interna, organizados em oligopólios e que, inseridos no sistema econômico capitalista, revelam-se como verdadeiros aparelhos privados de hegemonia (FONSECA, 2005, p. 27), visando os interesses das elites que dominam o mercado.

A partir da consideração de que as ameaças ao pluralismo democrático não advêm apenas do Estado, mas também das grandes organizações privadas — " [...] inclusive dos meios de comunicação de massa [...]" (HABERMAS, 2003a, p. 121) —, o presente trabalho tem a pretensão de refutar ponderações como as capitaneadas pela SIP. Sustentará

(1) Caso da França pré-revolucionária de 1789, onde os pequenos jornais surgiam "[...] por toda parte como capim" (HABERMAS, 2003b, p. 216)

(2) É o que sucedia no Brasil das primeiras décadas do século XIX, cuja imprensa era assim caracterizada: "jornal de um homem só, artesanal, mais doutrinário do que factual, impresso e vendido em tipografia, de linguagem veemente (por vezes agressiva e ofensiva), circulando com duas folhas e de periodicidade irregular." (MOREL; BARROS, 2003, p. 49) 
que políticas levadas a efeito pelos atuais governos dos países acima citados, por mais extremas que possam parecer (como as responsáveis por encerramento das atividades de emissoras de televisão), consistem em medidas aptas a tutelar a liberdade de expressão. Para isso, delineará as relações entre meios de comunicação e aparelho estatal decorrentes do processo de desenvolvimento do capitalismo e do advento do Estado de Bem-Estar Social, o Welfare State.

\section{A América latina sob o Domínio dos Oligopólios Midiáticos}

A estruturação dos meios de comunicação em oligopólios é produto direto da evolução do sistema econômico ora prevalente.

Com efeito, se a Europa das revoluções burguesas e a América Latina da libertação política testemunharam a multiplicação de uma imprensa amadora e plural é porque, em tais localidades, o capitalismo estava apenas no seu nascedouro. Com o passar dos anos, contudo, as inovações tecnológicas e a acumulação de capital em favor de trustes e cartéis impuseram a lógica da concentração:

A liberdade econômica, porque abria campo às manifestações do poder econômico, levou à supressão da concorrência. [...] O poder sobre as coisas engendra um poder pessoal; a propriedade, assim, de mero título para dispor de objetos materiais, se converte em um título de poder sobre as pessoas [...]. (GRAU, 2007, p. 22)

Nesses termos, os diversos impressos elaborados artesanalmente foram aos poucos substituídos por reduzido número de empresas altamente capitalizadas, as quais dominaram também as novas mídias advindas no decorrer do século XX - como rádio, televisão e internet ${ }^{(3)}$. Enquanto beneficiárias da concentração construída, tais organizações passaram, naturalmente, a exercer a função de trabalhar a opinião pública (HABERMAS, 2003b, p. 226) em favor da obediência voluntária dos cidadãos (COMPARATO, 2010, p. 1) às elites hegemônicas.

Eis um problema existente em praticamente todas as democracias estáveis ocidentais, dominadas pelo grande capital globalizado, propagandeado por trustes transnacionais midiáticos (MCCHESNEY, 2009, p. 219-236). Na América Latina, porém, este verdadeiro déficit democrático é acentuado por duas importantes peculiaridades historicamente ocorrentes na região.

A primeira encontra-se no fato de a concentração latino-americana ser liderada por reduzido número de grupos familiares que, ainda que inseridos na globalização por alianças com transnacionais sediadas no centro do capitalismo, mantém preponderantemente modelos de domínio centrados em figuras patriarcais (MASTRINI; BECERRA, 2001, p. 178). No ápice desta concentração, encontram-se cinco famílias, formadoras de um verdadeiro pentágono midiático do subcontinente (ULLOA, 2004, p. 237): a família

(3) Tal quadro deu ensejo à chamada propriedade cruzada, na qual as corporações de comunicação vieram a dominar concomitantemente diversas espécies de mídia. 
do venezuelano Gustavo Cisneros, proprietário das emissoras de televisão Univisión, Directtv, Chilevisión e Venevisión; dos mexicanos Emilio Azcárraga Jean e Carlos Slim Helú, donos da Televisa; da argentina Ernestina Herrera, titular do grupo Clarín; dos irmãos Marinho, do grupo brasileiro O Globo e, por fim, do mexicano Angel González, proprietário de quatro canais de televisão na Nicarágua, a Red TV Chile e dois no Peru. Além destes grupos familiares, existem outros que mantêm domínio em determinadas localidades: é o que ocorre na Bolívia, onde quatro organizações dominam $86 \%$ de todo mercado e, no Equador, onde 19 famílias controlam mais de 85\% das frequências de televisão aberta (MORAES, 2011, p. 40-42).

Importante assinalar que o poder adquirido por tais grupos normalmente tem sua origem em um arcabouço de favores recíprocos estabelecidos entre eles e determinadas elites políticas: as corporações familiares recebem, destas elites, concessões de rádio e televisão e, em troca, realizam propaganda política na programação regular da emissora. Cuida-se de sistema que em muito se assemelha ao velho coronelismo dominante nas primeiras décadas após a proclamação da república do Brasil, aparecendo as concessões de rádio e televisão como a moeda de troca dos favores políticos - o que justifica o uso da expressão coronelismo eletrônico (LIMA, 2007, p. 113-114). Apesar de aparentemente arcaico, este sistema tem se revelado eficiente, evidentemente para os interesses dos envolvidos, a ponto de ser um dos responsáveis pelo crescimento de corporações midiáticas situadas entre as maiores do mundo, como as Organizações Cisneros e as Organizações Globo.

A segunda peculiaridade encontra-se no fato de, ao longo da instável história política da região, muitos desses grupos terem promovido a propaganda de ações golpistas que levaram à ruptura de sistemas democráticos. Sem embargo de presente desde os primeiros anos de independência política da America Latina, tal trabalho intensificou-se a partir da segunda metade do século XX, época em que diversos países do subcontinente industrializaram-se mediante o processo de substituição de importações, em uma aliança que reuniu os respectivos Estados, as burguesias nacionais e o capital estrangeiro. A partir do momento em que explodiram as demandas das massas excluídas, os grupos midiáticos oligopolistas passaram uniformemente (levando o oligopólio na propriedade dos meios ao monopólio ideológico de informações) a apoiar movimentos golpistas promovidos por elites políticas e econômicas contra qualquer governo que fizesse concessões aos setores populares.

Há uma série de casos constatáveis empiricamente. Têm-se, assim, as ações das empresas de comunicação brasileiras Globo, O Estado de São Paulo e Folha da Manhã na derrubada de João Goulart em 1964. Há também o jornal El Mercurio do Chile, que não apenas deu suporte à queda do presidente Salvador Allende em 1973, como apoiou a ditadura de Pinochet, sem embargo das gravíssimas violações aos direitos humanos praticadas por quase duas décadas. Tem-se, ainda, o apoio concedido em 1976 pelos jornais El Clarín e La Nación ao golpe militar comandado por Jorge Videla na Argentina (BORGES, 2009, p. 36-38).

Recentemente, parte da grande mídia tornou a utilizar seus antigos métodos em momentos de instabilidade institucional. É o que sucedeu na tentativa de golpe de Estado 
na Venezuela promovida em 2002 contra o presidente Hugo Chávez, com a colaboração de quase totalidade das emissoras de televisão empresariais do país, a ponto de o episódio ser chamado de golpe midiático (ROVAI, 2007, p. 12).

O que se tem na América Latina, portanto, é uma situação aparentemente contraditória. Ao mesmo tempo em que transmite celeremente a amplas extensões territoriais as informações aptas a instruir os cidadãos nas tomadas de decisões que efetivam a influência popular nos governos democráticos, a grande mídia permanentemente ameaça as democracias locais, colocando-se como instrumento de ações golpistas contra qualquer governo que coloque em risco os interesses hegemônicos das elites.

\section{Concentração E Estado}

Todo o quadro acima descrito tem como pano de fundo jurídico-político a histórica desregulamentação estatal do sistema econômico.

De fato, o desenvolvimento do capitalismo deveu-se à assunção da burguesia como classe dominante a partir de eventos como a Revolução Gloriosa Inglesa (1688), a independência e a promulgação da Constituição dos Estados Unidos (1787) e a Revolução Francesa (1789). Em tal processo, na qualidade de grupo hegemônico, esta classe impôs seu próprio modelo de atuação estatal: ao poder público foram, assim, atribuídas as limitadas tarefas de manutenção da ordem interna e de defesa territorial contra os inimigos externos, o que, ao final, permitiu o livre crescimento das empresas detentoras de maior capital e a eliminação das concorrentes impossibilitadas do uso das inovações tecnológicas (e destituídas de qualquer proteção estatal eficaz contra o abuso do poder econômico das organizações de maior porte).

Esse foi o mesmo período em que se consagrou a liberdade de expressão, direito prontamente aplicado sob a idêntica lógica liberal de não atuação do Estado. As consequências deste fato foram semelhantes ao sucedido no sistema econômico como um todo, levando à eliminação da diversidade de panfletos amadores em favor de reduzidas empresas altamente capitalizadas, dotadas do poder de realizar a propaganda de um sistema favorável ao seu intuito lucrativo.

Ocorre que, assim como na grande maioria dos povos regidos por ordenamentos livres e democráticos, o Estado projetado nas Constituições dos países latino-americanos neste início de século XXI não é o Estado do período imediatamente posterior às revoluções burguesas. Como decorrência dos conflitos entre uma maioria excluída da expansão do capital e uma classe dominante que teve de ceder para não perder sua hegemonia (como sucedeu sob a Revolução Russa de 1917), o que se tem hoje é o Estado oriundo da evolução do constitucionalismo (BOBBIO, 2004, p. 18), o qual testemunhou, ao longo dos séculos, a positivação de uma série de direitos sociais e econômicos ${ }^{(4)}$ a exigirem, para a efetivação, a atuação positiva oficial:

(4) A Constituição do México de 1917 e a Constituição de Weimar de 1919 representam marcos introdutórios da constitucionalização de direitos sociais e econômicos. 
A lista de áreas potenciais para a ação do governo é grande. Hoje, quase todo mundo concorda que o governo precisa se envolver no fornecimento de educação básica, estruturas legais, infra-estrutura e de alguns elementos de uma rede de proteção social e na regulamentação da competição, dos bancos e dos impactos ambientais. (STIGLITZ, 2007, p. 122)

Se sob esse novo modelo, o Estado, conhecido como Welfare State, passou a ter o dever de atuar na efetivação de tantos direitos; inexiste qualquer motivo para que deixe de atuar na concretização da liberdade de expressão. Daí o reconhecimento da necessidade de promoção de medidas positivas para possibilitar aos cidadãos o recebimento de informações plurais e independentes de interesses meramente empresariais, neutralizando o poder dos oligopólios midiáticos em favor do dissenso de ideias.

Entende-se, então, a criação de emissoras de rádio e televisão controladas por diversos Estados europeus, como a BBC britânica, France Televisión francesa, RAI italiana, RTP portuguesa, TVE espanhola e ARD alemã. Entende-se, da mesma forma, a elaboração de normas que limitam a dimensão de empresas de comunicação e vedam a propriedade cruzada em determinadas áreas geográficas nos Estados Unidos da América (LIMA, 2006, p. 97-98).

Imperioso notar que quando se fala em atuação oficial, no âmbito do Welfare State, não se fala em eliminação da mídia privada. As lições oriundas dos regimes autocráticos vigentes no Leste Europeu sob o domínio soviético durante a Guerra Fria do século passado corroboram tal ilação. O que se fala, na realidade, é da necessidade de implementação de medidas que promovam o dissenso informativo, isentando a sociedade do monopólio da palavra — do governo ou do capital.

Remanesce, porém, saber se tais observações aplicam-se aos casos da Venezuela, Bolívia, Equador e Argentina, objetos de análises críticas como as realizadas pela SIP. Cabe investigar se as atuações oficiais sobre a mídia privada destes países realmente se fundam na efetivação da liberdade de expressão ou se caracterizam mera estratégia de supressão da mídia independente e opositora a interesses dos governos — tal como por diversas vezes ocorreu quando da instauração de sistemas autocráticos na região. Por isso, a necessidade de uma breve análise das políticas públicas recentemente promovidas em tais localidades.

\section{Políticas Públicas e Democratização dos Meios de Comunicação}

A Venezuela de Hugo Chávez, a Bolívia de Evo Morales, o Equador de Rafael Correa e a Argentina de Cristina Kirchner configuram verdadeiros paradigmas de uma tendência, ocorrente a partir do final do século XX na América Latina, de êxitos eleitorais à presidência da república de grupos oriundos de movimentos populares e alheios às antigas oligarquias que governaram a região desde sua independência política.

É certo que não há absoluta uniformidade em cada um dos projetos governamentais liderados pelos presidentes acima mencionados. Enquanto nos países andinos os novos grupos alcançaram o poder sob uma ambiciosa plataforma de superação do capitalismo em favor de uma nova realidade que denominam socialismo do século XXI, na Argentina, 
as novas elites políticas lograram a chefia do Executivo apresentando uma proposta meramente desenvolvimentista, baseada em políticas de transferência de renda (SANTOS, 2010, p. 25-26). Sem embargo desta distinção, em todos estes países, há em comum uma mídia empresarial que, não hesitando até mesmo promover uma tentativa de golpe de Estado como o da Venezuela em 2002 (ROVAI, 2007, p. 33-44), transformou-se em “[...] el gran 'partido' de oposición a la transformación progresista de la sociedad" (SANTOS, 2010, p. 55).

Tais circunstâncias não querem dizer que inexistam dúvidas acerca das reais intenções democráticas desses grupos - especialmente o liderado por um militar como Chávez, trazendo à memória os diversos regimes de exceção instaurados sob o comando castrense ao longo dos anos no subcontinente (PÁDUA; MATHIAS, 2010, p. 86). Entretanto, o fato é que todos esses grupos políticos, inclusive o da Venezuela, alcançaram o poder por meio de eleições livres, realizadas em conformidade às regras do jogo vigentes. E, logo que assumiram a presidência da república dos respectivos países, perduraram proporcionando juridicidade a seus programas de governo, fazendo até mesmo promulgar, pelas vias democráticas da eleição de parlamentares constituintes e do referendo popular, novas cartas constitucionais (à exceção da Argentina ainda regida pela Constituição de 1853 e reformada em 1994) ${ }^{(5)}$.

A obediência às regras do jogo também foi a característica das respostas de todos esses governos às campanhas opositoras promovidas pelos oligopólios midiáticos empresariais. Baseados em ordens jurídicas consagradoras de direitos fundamentais que impõem ao Estado condutas ativas para efetivação de todos os valores positivados, tais grupos passaram a instituir novos marcos normativos, aptos a democratizar os meios de comunicação.

Certamente, o ponto mais significativo desse processo, por sua amplitude, foi a aprovação no segundo semestre de 2009 da chamada Ley de Medios da Argentina. Por intermédio deste diploma legal, determinou-se a divisão das concessões de radiodifusão em três partes iguais à iniciativa privada, ao Estado e à sociedade civil; estipulou-se cotas de exibição para o cinema argentino e para programação educativa e dirigida à infância; determinou-se a submissão das novas concessões e das renovações das antigas concessões de radiodifusão a audiências públicas; e, dentre outras disposições, criou-se uma Autoridade Federal de sete membros e um Conselho Federal de 15 membros com a finalidade de garantir o cumprimento da lei (MORAES, 2010, p. 90).

Cerca de dois anos depois, o mesmo governo argentino conseguiu aprovar novo diploma legal, agora incidente sobre a mídia impressa, o qual definiu o papel-jornal como bem de interesse público. Não se cuida de medida de menor importância, ainda mais em um país que possui uma única fábrica do produto, cujas ações são em mais de $70 \%$ de propriedade de apenas dois periódicos (os jornais Clarín e La Nación). Com este marco normativo, segundo justificativas oficiais, permite-se que a produção do papel-jornal deixe de ser manipulada pelos princípios do mercado, atendendo ao interesse público (GUIMARÃES, 2011, p. 1).

(5) Em 1999, foi promulgada a nova Constituição da Venezuela; em 2007, foi aprovada a Constituição da Bolívia e, em 2008, a nova Constituição do Equador. 
Caminhos semelhantes foram os adotados nos países andinos ora discutidos. Neste sentido, tem-se o caso do governo venezuelano que logrou aprovar a Ley Orgánica de Telecomunicaciones em 2000 (impondo novas regras às outorgas e às renovações de concessões de emissoras de rádio e televisão) e a Ley de Responsabilidad Social en Radio y Televisión em 2004 (delineando a responsabilidade social de emissoras de rádio e televisão). No Equador, há a aprovação da Ley de Comunicaciones em 2011, que previu um conselho de regulação para coibir conteúdos de violência, discriminação e preconceito nas emissoras de radiodifusão e na mídia impressa (MORAES, 2011, p. 95). Preocupação semelhante teve o governo boliviano um ano antes, que fez aprovar lei que prevê a suspensão de concessão de emissoras de rádio e televisão que incorrerem em discriminação, representando uma importante conquista aos ativistas dos direitos humanos de um país cuja "[...] imprensa monopólica não esconde seus preconceitos contra os indígenas [...]" (SADER, 2008, p. 1).

Além desses diplomas normativos, os mesmos governos promoveram uma série de medidas concretas hábeis à divulgação plural de ideias. Na Argentina, destaca-se a criação da TV Encuentro, de propriedade do Estado, emissora que oficialmente objetiva a construção da cidadania pela priorização dos interesses comuns, transmitindo, para isso, programação educativa (MORAES, 2010, p. 85); na Venezuela, têm-se o incentivo à formação de meios comunitários oriundos da sociedade civil para a realização de contraponto às mensagens veiculadas pelas elites econômicas pela grande mídia (RIZZOTO, 2010, p. 305), o fortalecimento de emissoras de rádio e televisão estatais e a criação de jornais igualmente de propriedade oficial (TONETO, 2006, p. 78); na Bolívia e no Equador, também foram criados jornais estatais (o boliviano El Cambio instituído em 2008 e os equatorianos El Ciudadano e El Verdadero, fundados, respectivamente, em 2008 e em 2010); ainda, no Equador, foi instituída a Ecuador TV, cuja programação educativa recebeu duas das cinco premiações da I Mostra Ibero, Americana de Programas de Televisão Educativos, Culturais e Científicos em 2010. Por fim, há de se ressaltar a criação conjunta da empresa de televisão multiestatal Telesur (de propriedade comum dos Estados da Venezuela, Equador, Bolívia, Argentina, Nicarágua e Cuba), instituída em 2005 com o fim de promover a integração regional (MORAES, 2010, p. 65-66 e 73).

Todas essas medidas legislativas e administrativas foram objetos de intensa cobertura crítica por parte da grande mídia, especialmente dos meios brasileiros, comandados por aliados dos "[...] interesses de poderosos grupos de mídia locais [...]" (LIMA, 2009 , p. 1). Contudo, o fato é que nenhuma das providências oficiais aludidas impinge qualquer intimidação às tradicionais empresas midiáticas - a ponto de em todos esses países os meios oposicionistas perdurarem até hoje como instrumentos de propaganda dos grupos alijados do poder político pelos atuais governos. Tais providências limitam-se, na verdade, a retirar das organizações empresariais o monopólio da transmissão de informações, fomentando o dissenso de ideias que deve haver em qualquer democracia.

\section{Atuaç̃o Estatal e Concessões de Emissoras de Radiodifusão}

Interessante notar que a maioria das medidas governamentais acima citadas foi dirigida às emissoras de rádio e televisão. Evidentemente, há os impressos oficiais criados e até mesmo o caso da regulação de papel-jornal. Todavia, o que chama a atenção foi a 
preocupação generalizada dos governos citados na promoção de medidas como a distribuição de canais de radiodifusão a entidades não empresariais, o controle social sobre tais organizações e a tipificação de condutas infratoras pelas empresas que fazem uso da mídia eletrônica.

Essa cautela encontra sua razão de ser no fato de as emissoras comerciais de rádio e televisão fazerem emprego de um bem público, o espectro de radiofrequência, de possibilidade limitada de uso, de modo a ter sua disponibilidade restrita somente aos beneficiários de concessões públicas. As emissoras de radiodifusão, ainda que estabelecidas sob a forma de empresas racionalmente organizadas, prestam um serviço público, de titularidade do Estado (MELLO, 2007, p. 695).

Ao priorizar a mídia eletrônica, portanto, tais governos consideraram o dever de o proprietário de uma emissora de rádio ou de televisão prestar um serviço que não lhe pertence em conformidade ao interesse público. Em uma sociedade democrática, isto quer dizer, dentre outras exigências, obediência ao pluralismo de ideias e à vontade popular exprimida eleitoralmente - inclusive quando esta expressão ocorre em favor de grupos alheios aos velhos oligopólios midiáticos.

Daí a legitimidade democrática da não renovação, pelo governo venezuelano em 2007, da concessão da emissora empresarial Radio Caracas Televisión (RCTV), substituindo-a pelo canal estatal Televisora Venezolana Social (TEVES). Uma organização privada de comunicação jamais poderia exercer um serviço público para promover um golpe de Estado na forma do deflagrado na Venezuela em 2002 (VENEZUELA, 2007, p. 57-75).

Sob esse mesmo raciocínio, não será de se estranhar se o governo argentino passar a substituir canais empresariais de televisão por emissoras estatais ou pertencentes a entidades da sociedade civil, a fim de concretizar a partilha igualitária das concessões prevista na Ley de Medios. Da mesma forma, não será de se estranhar se os governos boliviano ou equatoriano suspenderem a concessão de uma emissora empresarial que veicular programação racista, a fim de darem cumprimento aos diplomas marcos legais que impõem sanções a condutas discriminatórias.

Note-se que medidas, como a efetivamente aplicada na Venezuela e, em tese, aplicáveis na Argentina, Equador e Bolívia, não consistem em peculiaridades do subcontinente. Nos Estados Unidos da América e na Europa Ocidental, providências semelhantes já foram tomadas. São casos como os das 141 concessões extintas entre 1934 e 1987 pelo Conselho Federal de Comunicações estadunidense, da extinção da concessão de TV católica pelo governo espanhol em 2005 e da retirada, no mesmo ano, pelo governo francês do direito da emissora TFl transmitir sua programação pelo fato de esta ter negado a existência do Holocausto (BORGES, 2009, p. 97-98).

\section{Conclusão}

As políticas públicas de comunicação social promovidas pelos governos da Argentina, da Bolívia, do Equador e da Venezuela têm sido marcadas pela legitimidade. Trata-se, 
em geral, de atuações aptas a fomentar o pluralismo de opiniões, sob o amparo de ordenamentos jurídicos que impõem ao Estado o dever de agir na efetivação dos direitos fundamentais, no que se inclui a liberdade de expressão.

Não se nega que sempre existe a possibilidade de os governos promoverem medidas, como as analisadas, na forma de estratégia de eliminação da mídia independente, assumindo arbitrariamente o monopólio da palavra. Afinal, como já dizia James Madison (2000, p. 331), os homens não são governados por anjos. Todavia, ao menos por ora, prevalecem providências favoráveis à democratização dos meios de comunicação, rompendo o velho coronelismo que, até então, havia caracterizado a construção da estrutura midiática desses países.

Espera-se que os exemplos citados sirvam de modelo para toda a América Latina, onde a liberdade de expressão é predominantemente exercida em favor dos oligopólios de comunicação - mesmo quando estes se encontram submetidos ao regime das concessões - baseado em uma anacrônica interpretação liberal do direito à palavra. Tudo isso, como se as ameaças à democracia viessem apenas de ações governamentais e não também de campanhas propagandistas, inclusive golpistas, levadas e efeito por corporações privadas.

\section{BiBLIOGRAFIA}

BOBBIO, Noberto. Teoria geral da política: a filosofia política e as lições dos clássicos. Rio de Janeiro: Elsevier, 2000. 717p.

A Era dos Direitos. 9. ed. Rio de Janeiro: Elsevier, 2004. 212p.

BORGES, Altamiro. A ditadura da mídia. São Paulo: Anita Garibaldi; Associação Vermelho, 2009. 176p. COMPARATO, Fábio Konder. Para que o povo tenha a palavra. Observatório da Imprensa. São Paulo, n. 587,27 abr. 2010. 1p. Disponível em: <http://www.observatoriodaimprensa.com.br/artigos. asp? cod=587CID002>. Acesso em: 27 abr. 2010.

FONSECA, Francisco. O consenso forjado: a grande imprensa e a formação da agenda ultraliberal no Brasil. São Paulo: Hucitec, 2005. 461p.

GRAU, Eros Roberto. A ordem econômica na Constituição de 1988. 12. ed. São Paulo: Malheiros, 2007. 391p.

GUIMARÃES, Marina. Lei torna papel-jornal de "interesse público". Observatório da imprensa. São Paulo, n. 674, 27 dez. 2011. 1p. Disponível em:<http://www.observatoriodaimprensa.com.br/news/ view/_ed674_lei_torna_papel_jornal_de_interesse_publico> Acesso em: 27 dez. 2011.

HABERMAS, Jürgen. Direito e democracia entre facticidade e validade. Rio de Janeiro: Tempo Brasileiro. 2003a, v. 2. 352p.

. Mudança estrutural na esfera pública. 2. ed. Rio de Janeiro: Tempo Brasileiro, 2003b. 397p.

LIMA, Venício A. de. Mídia: crise política e poder no Brasil. São Paulo: Fundação Perseu Abramo, 2006. 174p.

As "brechas" legais do coronelismo eletrônico. Aurora: revista digital de arte, mídia e política da Pontifícia Universidade Católica de São Paulo, São Paulo, n. 1, p. 113- 126, dez. 2007.

Cristina fez o que Lula não fez. Observatório da imprensa, São Paulo, n. 677, 20 out. 2009. 1p. Disponível em: <http://www.observatoriodaimprensa.com.br/news/view/cristina_fez_o_ que_lula_nao_fez> Acesso em: 20 out. 2009. 
. Liberdade de expressão x liberdade de imprensa: direito à comunicação e democracia. São Paulo: Publisher Brasil, 2010. p. 157.

MADISON, James. The federalist number 51. In: MADISON, James; HAMILTON, Alexander; JAY, John. The federalist: a comentary on the Constitution of the United States. New York: The Modern Library Edition, 2000. p. 330-335.

MASTRINI, Guillhermo; BECERRA, Martín. 50 años de concentración de medios en América Latina: del patriarcado artesanal a la valorización en escala. In: QUIRÓS FERNÁNDEZ, F; SIERRA CABALLERO, F. (eds.): Globalización, comunicación y democracia. Crítica de la economía política de la comunicación y la cultura. Sevilla:Comunicación Social Ediciones y Publicaciones, 2001. p. 179-208. MCCHESNEY, Robert W. Mídia global, neoliberalismo e imperialismo. In: MORAES, Denis de. Por uma outra comunicação: mídia, mundialização cultural e poder. 4. ed. Rio de Janeiro: Record, 2009. p. 217-242.

MELLO, Celso Antônio Bandeira de. Curso de Direito Administrativo. 24. ed. São Paulo: Malheiros, 2007. 1063p.

MORAES, Denis de. Vozes abertas da América Latina: Estado, políticas públicas e democratização da comunicação. Rio de Janeiro: Mauad X; Faperj, 2011. 207p.

MOREL, Manoel; BARROS, Mariana Monteiro de. Palavra, imageme poder: o surgimento na imprensa no Brasil do século XIX. Rio de Janeiro: DP \& A, 2003. 130p.

PÁDUA, Adriana Suzart de; MATHIAS, Suzeley Kalil. Venezuela: qual democracia? Revista Cadernos Prolam/USP. Brazilian Journal of Latin America Studies. São Paulo, v. 2, p. 69-88, 2010.

RIZZOTTO, Carla Candida. Concentração de mídias e políticas de comunicação na Venezuela. Estudos em jornalismo e mídia da Universidade Federal de Santa Catarina, Florianópolis, v. 7, n. 2, p. 297-310, 2010.

ROVAI, Renato. Midiático poder: o caso da Venezuela e a guerrilha informativa. São Paulo: Publisher Brasil, 2007. 167p.

SADER, Emir. O racismo separatista. Blog do Emir. São Paulo, 29 abr. 2008. 1p. Disponível em: http://www.cartamaior.com.br/templates/postMostrar.cfm?blog_id=1\&post_id=178 Acesso em: 20 jan. 2012.

SANTOS, Boaventura de Sousa. Refundación del Estado en América Latina: perspectivas desde una epistemologia del Sur. Lima: Instituto Internacional de Derecho y Sociedad; Programa Democracia y Transformación Global, 2010. 154p.

SOCIEDADE INTERAMERICANA DE IMPRENSA. Comunicado. Lima, 12 out. 2011. 1p. Disponível em: http://www.sipiapa.org/v4/comunicados_de_prensa.php? seccion=detalles\&id=4632\&idioma =br Acesso em: 12 out. 2011.

STIGLITZ, Joseph E. Globalização: como dar certo. São Paulo: Companhia das Letras, 2007. 523p. TONETO, Maria Bernardete. O cerco rompido: do monopólio dos meios de comunicação à participação popular no Brasil e Venezuela. 2006. Dissertação (Mestrado em Integração da América Latina) — Programa de Pós-graduação em Integração da América Latina, Universidade de São Paulo, São Paulo, 2006. 113p.

ULLOA, Ernesto Carmona. Los dueños de Venezuela (...y los amos de la presna de America Latina). Santiago: Ediciones del Leopardo; Revista Punto Final, 2004. 232p.

VENEZUELA. Libro blanco sobre RCTV (2007). Caracas, Ministerio del poder popular para la comuncación y la información, 2007. 1p. Disponível em: <http://www.rnv.gov.ve/noticias/docs/ libro_blanco_RCTV-Web.pdf> Acesso em: 22 fev. 2011. 